\title{
Assessment of Attitude towards Substance Abuse among Community in Kebele 08, Harar Town, Eastern Ethiopia
}

\author{
Selam Bogale and Teshome Sosengo* \\ School of Pharmacy, College of Health and Medical Sciences, Haramaya University, \\ Ethiopia \\ *Corresponding Author: Teshome Sosengo, School of Pharmacy, College of Health \\ and Medical Sciences, Haramaya University, Ethiopia.
}

Received: April 29, 2021

Published: May 20, 2021

(C) All rights are reserved by Selam Bogale

and Teshome Sosengo.

\begin{abstract}
Background: The problem of social drugs utilization is an emerging and serious problem in the world. According to 2017 United Nation world drug report, around 29.5 million drug abusers were exposed to serious illnesses and 11.4 million deaths were related to drug abuse.

Objective: To assess attitude toward substance abuse abuse among the community of kebele 08 community, Shenkor Woreda, Harar town, Eastern Ethiopia from December 10, 2020 to February 01, 2021.

Methodology: Community based cross-sectional study using a pre-tested structured self-administered questionnaire was conducted from December10, 2020 to February 01, 2021. Simple random sampling technique was used to select 379 respondents from kebele 08, Shenkor worede, Harar town, Eastern Ethiopia residents. The data collection was done using a self-administered structured questionnaire and the data was entered and analyzed by using statistical package for social science version 24 . The result is presented in tables.

Result: Out of the total 403 community members invited to fill the questionnaire, the 379 respondents participated in the study with a response rate of $94.5 \%$. The $55.7 \%$ and $44.3 \%$ respondents were male and female respectively. The $74.4 \%$ of the study participants replied that health education is important regarding prevention of substance abuse. The $43.8 \%$ of the study respondents believe that boys who smoke have more friends than those do not smoke. The $77 \%$ reported that it is difficult to stop once someone started smoking. The $63.3 \%$ of respondents oppose practice of Khat chewing. The $28.8 \%$ of the respondents replied that they will try to practice drinking alcohol, khat or cigarette at any time in the future. The respondents reported that they think the one who smokes Cigarette as the one who lacks confidence $25.1 \%$ as a loser (23\%), stupid (16.9\%) and sophisticated (16.6\%).

Conclusion: Majority of the participants have negative attitude toward those who abuse substance especially toward those who smoke cigarette. In the current study majority of the respondents believes that health education is important for prevention of substances abuse.
\end{abstract}

Keywords: Alcohol; Attitude; Cigarette; Khat; Substance Abuse

\section{Introduction}

The problem of social drugs utilization is an emerging and serious problem in the world. According to 2017 United Nation World drug report, around 29.5 million drug abusers were exposed to serious illnesses and 11.4 million deaths were related to drug abuse. Social drugs utilization has a negative consequence on the economic development of a country as the health, time and money of the most productive section of human resource (youngsters) are affected by the habit of indulging in drugs [1].

Globally, 9.8\% of women consume alcohol while they are pregnant [2]. In 2016, in Eastern Africa WHO region, the estimated prevalence of alcohol consumption during pregnancy among the general population ranged from $3.4 \%$ in Seychelles to $20.5 \%$ 
in Uganda and $7.9 \%$ in Ethiopia [3]. Alcohol is one of commonly abused social substance among youth population of Ethiopia [4,5].

The other commonly abused substance is tobacco. The tobacco epidemics continue to shift from high-income countries to low- and middle-income countries, with a recent increase in the prevalence of tobacco smoking among women, which is expected to rise to $20 \%$ by $2025[6,7]$. Based on 2011 Ethiopian demographic health survey (EDHS) data analysis, the overall prevalence of tobacco use was $4.1 \%, 8.1 \%$ and $0.8 \%$ among adults, adult males and females respectively [8]. Every year, more than 16,800 Ethiopians are killed by tobacco-related diseases such as tuberculosis, lung cancer, cardiovascular and respiratory disorders $[9,10]$.

The other deleterious impacts a substance abuse is associated with abuse one Khat. Khat use has been associated with physical illness, injuries, under nutrition, mental distress, sleep disorders, problem drinking and heavy smoking. In a study done in Butajira, Ethiopia in over 10,000 adults shows a higher prevalence of mental distress and suicide attempt was found in those using alcohol and khat $[5,11]$.

The negative consequences of substance abuse affect not only individuals who abuse substances but also their families, friends, various businesses and government resources. Substance abuse and dependence have grave consequences for existing social systems, affecting crime rates, hospitalizations, child abuse and neglect, and rapidly consuming public funds [12-14]. Substance misuse is associated with psychological distress, suicide attempts functional impairment, physical ill- health and risk-taking behavior [15-17].

Although abuse of substances, alcohol consumption, chat chewing and cigarette smoking have become common practices among community, no study has assessed the attitude towards substance abuse among Shenkor Woreda, kebele 08 community.

\section{Objective of the Study}

The objective of this study is to assess the attitude toward substance abuse among the community of Shenkor woreda, kebele 08 community in Harar town, Eastern Ethiopia.

\section{Methodology}

\section{Study setting and period}

The study was conducted in Kebele 08, Shenkor, Woreda, Harar town from December10, 2020 to February 01, 2021 among Shenkor Woreda, kebele 08 residents in Harar town, Eastern Ethiopia. Harar is a city located in Eastern Ethiopia, $526 \mathrm{kms}$ from Addis Ababa. The total numbers of kebele of the city are 19 , while the

rural part of the State has 17 farmers associations. The State's size is estimated at $340 \mathrm{~km}^{2}$. Based on the 2012 census conducted by central statistics agency, the Harari national regional states' (HNRS) total population is 263,657 and 67,604 households. The percentage share of males and females is about $50 \%$ each. The urban residents of the State were 154,380 and its rural inhabitants were 109,276 .

\section{Study design}

Community based cross-sectional study was conducted among Shenkore Woreda, kebele 08 community to assess attitude towards substance abuse.

\section{Population}

Source and study population

- The source population was all residents of Shenkor Woreda kebele 08 of Harar twon.

\section{Study population}

- $\quad$ The study population was individuals aged greater than 15 years and living for at least six months in the town.

\section{Sample size determination}

Sample size was determined using single population proportion formula for cross-sectional study. To obtain maximum sample size at $95 \%$ certainty and a maximum discrepancy of $\pm 5 \%$ was used. The following formula was used to calculate the sample size:

$n i=\frac{(Z \alpha / 2)^{2}}{d^{2}} \underline{P}(1-P)$

Where;

$\mathrm{ni}=$ The desired sample size

$\mathrm{p}=$ Prevalence of substance abuse among community (50\%) (since no study was conducted in the study area as far as the investigator knowledge and searching effort)

$\mathrm{Z} \alpha / 2=$ Critical value at $95 \%$ confidence level of certainty (1.96)

$\mathrm{d}=$ The margin of error between the sample and the population $=$ $5 \%$

$\mathrm{n}==384$

Using the above formula, sample size (ni) $=384$, since our sample population $(\mathrm{N})$ is less than 10000 (i.e). The following formula was used to calculate the exact sample size(nf).

$\mathrm{nf}=\mathrm{nixN} / \mathrm{ni}+\mathrm{N}$, which results in sample size of 367 . With additional $10 \%$ for contingency for non-response, the final sample size became 403 . 
Sampling procedures

First the study kebele was selected by lottery method from 19 kebeles found in the town. Then, the sample was selected by using simple random sampling.

\section{Data quality control}

In order to assure data quality, high emphasis was given to minimize errors using the following strategies: the questionnaire was pretested and subsequent correction and modification was done, and proper instruction was given before the survey was started. The collected data was reviewed and checked for completeness before data entry.

\section{Data processing and analysis}

The collected data was coded, entered and analyzed with SPSS version 24 and the result is presented by tables.

\section{Ethical considerations}

The study was carried out after letter of permission obtained from school of pharmacy, Haramaya University College of Health and Medical Science. Confidentiality was assured and full written informed consent was obtained from all participants before actual data collection.

\section{Operational definitions}

- Alcoholic drinks: Any drink like "tela," "tej," "katicala/ areke", beer, wine or other drinks that can cause intoxication.

- Attitude: Ways of thinking or feeling, which will drive a person to do or not to do things.

- Substances: Any non-medical drugs used by study subjects such as alcohol, khat, tobacco, cannabis, heroin, cocaine and marijuana to alter their mood or behaviour.

- Substance abuse: A condition in which the person uses a drug over and over again, in ways that hurt their health.

\section{Result and Discussion}

\section{Socio-demographic characteristics}

Out of the total 403 community members invited to fill the questionnaire, the 379 respondents participated in the study with a response rate of $94.5 \%$. The 211 (55.7\%) and 168(44.3\%) respondents were male and female respectively. Most of the study participants belong to an age group of $15-24$ years $(32.5 \%)$ and 25-34years (25.6\%).

The $10.8 \%$ of the participants were illiterate and $26.6 \%$ have completed primary education. With regard to occupation
$110(29 \%)$ of the respondents are unemployed and $89(23.55)$ of the respondents were government employees. The 172 (45.4\%) and $158(41.7 \%)$ respondents were orthodox and Muslims respectively by their religion.

With respect to marital status, the $167(44.1 \%)$ and $166(43.8 \%)$ were single and married respectively. The monthly household income of the majority (59.9\%) of the participants was below 1000 Ethiopian birr (Table 1).

\begin{tabular}{|c|c|c|}
\hline Variable & Frequency & Percentage (\%) \\
\hline \multicolumn{3}{|l|}{ Sex } \\
\hline Male & 211 & 55.7 \\
\hline Female & 168 & 44.3 \\
\hline \multicolumn{3}{|l|}{ Age } \\
\hline $15-24$ & 123 & 32.5 \\
\hline $25-34$ & 97 & 25.6 \\
\hline $35-44$ & 61 & 16.1 \\
\hline $45-54$ & 56 & 14.8 \\
\hline$>55$ & 42 & 11.1 \\
\hline \multicolumn{3}{|l|}{ Educational status } \\
\hline Illiterate & 41 & 10.8 \\
\hline Read and write & 82 & 21.6 \\
\hline Primary school & 101 & 26. \\
\hline Secondary school & 83 & 21.9 \\
\hline Collage/University & 72 & 19 \\
\hline \multicolumn{3}{|l|}{ Occupation } \\
\hline Government & 89 & 23.5 \\
\hline Private sector & 67 & 17.7 \\
\hline Self employed & 81 & 21.4 \\
\hline Daily labor & 32 & 8.4 \\
\hline I have no work & 110 & 29 \\
\hline \multicolumn{3}{|l|}{ Religion } \\
\hline Orthodox & 172 & 45.4 \\
\hline Muslim & 158 & 41.7 \\
\hline Protestant & 40 & 10.6 \\
\hline Catholic & 5 & 1.3 \\
\hline Other* & 4 & 1.1 \\
\hline \multicolumn{3}{|l|}{ Marital status } \\
\hline Single & 167 & 44.1 \\
\hline Married & 166 & 43.8 \\
\hline Divorced & 28 & 7.4 \\
\hline Widowed & 18 & 4.7 \\
\hline \multicolumn{3}{|l|}{ Monthly income } \\
\hline$<1000$ & 227 & 59.9 \\
\hline $1000-5000$ & 117 & 30.9 \\
\hline $5000-10000$ & 23 & 6.1 \\
\hline$>\quad 10000$ & 12 & 3.2 \\
\hline Other*: No religion & & \\
\hline
\end{tabular}

Table 1: Socio-demographic characteristics of the study participants kebele 08, Harar town, Eastern Ethiopia, February 2021. 
Attitude of the community towards substance abuse

The $74.4 \%$ of the participants believed that health education is important regarding prevention of substance abuse. This result is better than study Undertaken in Ethiopia at Jimma University that showed that the $60.5 \%$ of substance abusers suggested that health education can help in reducing poly drug use in their campus and their country as a whole [18].

The $43.8 \%$ of the study respondents believe that boys who smoke have more friends than those do not smoke while the $33.2 \%$ believed boys who smoke has fewer friends and the remaining $23 \%$ believed there is no difference from non-smoker. This finding is in contrary the finding of a study done in Jordan University, which showed that $19 \%$ respondents believe that smokers have more friends than non-smokers [19].

Regarding attitudes toward khat chewing habit, $63.3 \%$ of the respondents oppose practice of Khat chewing. This result is by far better than study result of study done in Lagos, Nigeria in which $44.4 \%$ of the respondents feel that someone should use substances to boost performance [20].

The $56.2 \%$ of the respondents replied that they will try to practice drinking alcohol, khat or cigarette at any time in the future and the $43.8 \%$ of them have not thought to try at all. This finding is better than study report of study done at Cairo Egypt, in which $60 \%$ stated that they would even smoke in front of their parents [21]. Since negative attitude towards substance abuse results in practice of substance abuse at some time in life and exposes the population to the negative impacts of substance abuse such as increased economic expense, increased mortality and morbidity, breaking of homes, increased crimes and delete ration of economic growth of the country in general, appropriate action that creates positive attitude on the population about substance abuse should be given [22-25].

The participants reported they that smoke cigar rete lacks confidence $95(25.1 \%)$, as a loser (23\%), stupid (16.9\%) and sophisticated $(16.6 \%)$. This result is by far better than report of study performed at Eastern Kenya, in which 93\% of the study respondents replied that smoking Cigar rete makes the smoker cool [26] (Table 2).

\begin{tabular}{|c|c|c|c|}
\hline $\begin{array}{c}\text { Variable Attitude } \\
\text { towards } \\
\text { substance abuse }\end{array}$ & & $\begin{array}{c}\text { Fre- } \\
\text { quency }\end{array}$ & $\begin{array}{c}\text { Per- } \\
\text { centage } \\
(\%)\end{array}$ \\
\hline Health education is & Yes & 282 & 74.4 \\
\hline important regarding & No & 97 & 25.6 \\
\hline $\begin{array}{c}\text { prevention of sub- } \\
\text { stance }\end{array}$ & Definitely not & 203 & 53.6 \\
\hline Abuse? & Probably not & 37 & 9.8 \\
\hline If one of your best & Probably yes & 57 & 15 \\
\hline $\begin{array}{c}\text { friends offered you a } \\
\text { cigarette, would you } \\
\text { smoke it? }\end{array}$ & Definitely yes & 82 & 21.6 \\
\hline Do you think boys who & More friends & 166 & 43.8 \\
\hline smoke cigarettes have & Less friends & 126 & 33.2 \\
\hline more or less friends & $\begin{array}{c}\text { No difference from } \\
\text { non-smoker }\end{array}$ & 87 & 23 \\
\hline Do you think you will & Definitely not & 61 & 16.1 \\
\hline be smoking cigarettes & Probably not & 100 & 26.4 \\
\hline 5 years from now? & Probably yes & 65 & 17.2 \\
\hline & Definitely yes & 153 & 40.4 \\
\hline & Strongly agree & 149 & 39.3 \\
\hline Do you agree that it & Agree & 143 & 37.7 \\
\hline would be & Disagree & 56 & 14.8 \\
\hline difficult to quit once & Strongly disagree & 31 & 8.2 \\
\hline someone & Yes & 240 & 63.3 \\
\hline has started smoking? & No & 139 & 36.7 \\
\hline Do you oppose prac- & Yes & 109 & 28.8 \\
\hline tice of Khat chewing? & No & 166 & 43.8 \\
\hline & Probably & 104 & 27.4 \\
\hline Do you think you will & & & \\
\hline try any of alcohol, khat & He /she lacks confi- & 95 & 25.1 \\
\hline or cigarette at any time & dence & 64 & 16.9 \\
\hline & $\mathrm{He} /$ she is stupid & 87 & 23 \\
\hline & $\mathrm{He} / \mathrm{she}$ is a loser & 12 & 3.2 \\
\hline When you see a man/ & $\mathrm{He} /$ she is successful & 17 & 4.5 \\
\hline woman smoking what & $\mathrm{He} /$ she is intelligent & 41 & 10.8 \\
\hline $\begin{array}{c}\text { do you think of him/ } \\
\text { her? }\end{array}$ & $\begin{array}{l}\mathrm{He} / \mathrm{she} \text { is a real man/ } \\
\text { woman } \\
\mathrm{He} / \text { she is sophisti- } \\
\text { cated }\end{array}$ & 63 & 16.6 \\
\hline
\end{tabular}

Table 2: Attitude towards substance among the respondents kebele 08, shenkor woreda, Harar town, February, 2021. 
The $67.3 \%$ of study participants replied that the health of nonsmoker can be affected by passive smoking. This is slightly lower than report a survey done in South Africa on national representative sample of 2,238 adult ( $>18$ years), where $71 \%$ of the respondents thought that the health of non-smoker is affected by smokers in the household (Reddy., et al. 2014). The discrepancy may due to difference in study setting and population.

\section{Conclusion and Recommendation}

Majority of the participants have negative attitude toward those who abuse substance especially toward those who smoke cigarette. In the current study majority of the respondents believes that health education is important for prevention of substances abuse. Since negative attitude towards substance abuse results in high prevalence of practice of substance abuse and hence its deleterious effects of substance abuse on health, appropriate bodies should intervene by giving health education targeted towards creation of positive attitude towards substance abuse and hence prevention of deleterious effects of substance abuse on health.

\section{Acknowledgement}

The authors acknowledges Harmaya University College of health and medical Sciences for all positive co-operations for the undertaking of this study.

\section{Consent to Publish}

Not applicable.

\section{Funding}

None.

\section{Competing Interests}

The author declare no competing interest.

\section{Author's Contribution}

Author Selam Bogale involved in the conception and design of the study, participated in the literature searches, analyzed data and wrote the manuscript. Author Teshome Sosengo involved in the conception and design of the study, participated in the literature searches, supervised data collection and analyzed data. Both the authors approved the final manuscript.

\section{Availability of Data}

All the data are available with the primary author, Selam Bogale.

\section{Bibliography}

1. UNODC. "World drug report". New York united Nations. Vienna, Austria (2018).

2. Popova S., et al. "Global prevalence of alcohol use and binge drinking during pregnancy and fetal alcohol spectrum disorder". Biochemistry and Cell Biology 114.7 (2017): 1150-1172.

3. Popova S., et al. "Actual and predicted prevalence of alcohol consumption during pregnancy in the WHO African Region". Tropical Medicine and International Health 21.10 (2016): 1209-1239.

4. Awell Y., et al. "Socio-economic and health effects of Khatchewing in Mekelle, Tigray Region. Ethiopia". IJPPR 8.1 (2016): 11-22.

5. Fekadu A., et al. "Alcohol and Drug Abuse in Ethiopia: Past, Present and Future". African Journal of Drug and Alcohol Studies 6.1 (2007): 39-53.

6. WHO. "WHO recommendations for the prevention and management of tobacco use and second-hand Smoke exposure in pregnancy". Switzerland, Geneva (2013).

7. Masibo RM., et al. "An assessment of knowledge, attitudes and practices of psychoactive substance use among secondary school students in Dodoma Municipality, Tanzania”. American Journal of Research Communication (2013): 200-240.

8. Lakew Y and Haile D. "Tobacco use and associated factors among adults in Ethiopia: further analysis of the 2011 Ethiopian demographic and health survey". BMC Public Health 15 (2015): 487.

9. Tobacco Atlas. Issues- Ethiopia. American Cancer Society, Vital Strategies (2015).

10. Ayenew M., et al. "Prevalence and factors associated with substance use among street children in Jimma town, Oromiya national regional state, Ethiopia: a community based crosssectional study". Substance Abuse Treatment, Prevention, and Policy 15.61 (2020): 1-9.

11. Gobeje A., et al. "Prevalence of substance use and associated factors among preparatory students of N/Wollo Woldia Town, North East Ethiopia, 2015". Acta Scientific Nutritional Health 3.2 (2019): 25-33. 
12. Nurul IA., et al. "Knowledge, attitude and practice towards smoking among International Islamic University Malaysia Kuantan communities". International Medical Journal Malaysia 15.2 (2016): 19-25.

13. Morales E., et al. "Cannabis use in secondary-school pupils in Barcelona: initiation, effects experienced and expectations". Gaceta Sanitaria 22 (2008): 321-329.

14. Etana BM. "Economic and Social Impacts of Khat (Catha edulis Orsk) Chewing Among Youth in Sebeta Town, Oromia Ethiopia”. Biomedical Statistics and Informatics 3.2 (2018): 29-33.

15. Kotina S., et al. "A study to determine causes, prevalence and knowledge regarding consequences of substance abuse: a community based cross sectional study". International Journal of Community Medicine and Public Health 3 (2016): 730-734.

16. Jaber D., et al. "Knowledge, Attitude and Opinion of Drug Misuse and Abuse by Pharmacy Students: A Cross-Sectional Study in Jordan". Tropical Journal of Pharmaceutical Research 14.8 (2015): 1501-1508.

17. Ramos MM., et al. "Adolescent substance use: Assessing the knowledge, attitudes, and practices of a school-based health center workforce". Journal of Substance Abuse 38.2 (2017): 230-236.

18. Kalayu M., et al. "Effect of substance use on academic achievement of health officer and medical students of Jimma University, Southwest Ethiopia”. Ethiopian Journal of Health Science 19.3 (2009): 155-163.

19. Sharif L., et al. "Knowledge, attitude and practice of university students towards smoking in Irbid, Jordan". Journal of Public Health and Epidemiology 5.1 (2013): 29-36.

20. Molobe ID. "Knowledge, Attitude and Practice on Drug Abuse among Sports Men and Women in Lagos State, Nigeria". International Journal of Medicine and Medical Sciences 2.3 (2012): 077-085.

21. Shalaby SF and Soliman MA. "Knowledge, attitude, and practice of medical students regarding smoking and substance abuse, Cairo University, Egypt". Journal of the Egyptian Public Health Association 94.11 (2019): 1-9.
22. Priyadarshini SR., et al. "Knowledge, attitude and practice of dental professionals towards substance use". Journal of International Society of Preventive and Community Dentistry 9 (2019): 65-71.

23. Olatona FA., et al. "Knowledge, attitude and practice of drug abuse among public secondary school students In Lagos". Highland Medical Research Journal 13 (2013): 44-48.

24. Liranso GS., et al. "Drug and Substance Abuse Knowledge and Attitudes among Youth in Addis Ababa Ethiopia”. Journal of Substance Abuse Treatment 5.2 (2017): 1056.

25. Njoroge MW. "Knowledge, Attitude and Practices on Substance Use Disorders by University Students: A Review of Literature". Drug and Alcohol Dependence 5.291 (2017): 1-5.

26. Embleton L., et al. "Knowledge, Attitudes, and Substance Use Practices Among Street Children in Western Kenya". Substance Use and Misuse 47 (2012): 1234-1247.

Volume 5 Issue 6 June 2021 (C) All rights are reserved by Selam Bogale and Teshome Sosengo. 